\title{
Angiolymphoid hyperplasia with eosinophilia presenting as an axillary artery aneurysm
}

\author{
Neil Kukreja, ${ }^{1}$ Matthias Koslowski, ${ }^{2}$ Robert Insall ${ }^{3}$ \\ 'Department of Surgery, St Thomas' Hospital, London, UK; \\ 2Department of Histopathology, William Harvey Hospital, Ashford, UK; \\ ${ }^{3}$ Kent and Canterbury Hospital, Canterbury, UK \\ Correspondence to Neil Kukreja, neil.kukreja@gmail.com
}

\begin{abstract}
Summary
A man in his late 20s presented with a painless swelling in his left axilla accompanied with nocturnal sweating. On examination, there was a well circumscribed, pulsatile lump within the axilla. Subsequent imaging revealed an axillary artery aneurysm with thrombus within. Subsequent surgical repair was undertaken. Subsequent histological examination of the vessel revealed features characteristic of angiolymphoid hyperplasia with eosinophilia.
\end{abstract}

\section{BACKGROUND}

This is a rare cause of an axillary artery aneurysm in a young patient and brings together dermatology, rheumatology and vascular surgery.

\section{CASE PRESENTATION}

A man in his late 20 s presented with a painless swelling in his left axilla. He also had a long history of nocturnal sweating with no history of weight loss or fatigue. On examination, there was a large, well circumscribed lump measuring $3 \times 2.5 \mathrm{~cm}$ within the apex of the left axilla. The mass was pulsatile, firm and non-tender. General examination was otherwise unremarkable; in particular, there were neither skin lesions nor palpable lymphadenopathy.

\section{INVESTIGATIONS}

Biochemical and haematological investigations were normal apart from a mildly raised eosinophil count of $0.5 \times$ $10^{9} / 1$ (upper limit of normal $0.4 \times 10^{9} / 1$ ).

Doppler ultrasound confirmed a $2.9 \mathrm{~cm}$ long $\times 1.8 \mathrm{~cm}$ wide aneurysm of the distal axillary artery with evidence of an irregular thrombus present within.

\section{DIFFERENTIAL DIAGNOSIS}

Angiolymphoid hyperplasia with eosinophilia (ALHE) has been known by a variety of different names, such as epithelioid haemangioma, pseudopyogenic granuloma, inflammatory angiomatous nodule, papular angioplasia, subcutaneous angioblastic lymphoid hyperplasia with eosinophilia and lymphofolliculosis, intravenous atypical vascular proliferation and histiocytoid haemangioma. ${ }^{1}$ This extensive list of nomenclature reflects the spectral variation in microscopic presentations of ALHE encountered by past investigators and, not least, the divided opinion as to whether the pathogenesis of the lesion is truly neoplastic or a reactive phenomenon.

There has been controversy over the exact relationship between Kimura's disease (KD) and ALHE, where the two terms have been used interchangeably in many articles. KD was first described by Chinese authors Kimm and Szeto ${ }^{2}$ in 1937 and later made widely recognised by Kimura in 1947. KD is a chronic inflammatory disease of unknown aetiology usually presenting as solitary or multiple subcutaneous nodules in the head and neck region, often involving the parotid or submandibular salivary glands. KD is associated with regional lymphadenopathy; this may become generalised in longstanding disease ${ }^{3}$ and systemic eosinophilia with raised IgE levels. It is most prevalent in Asians with $85 \%$ of cases occurring in males.

Although $\mathrm{KD}$ has been thought to be integral to the spectrum of ALHE in the past, histological features show that these conditions represent two separate disease entities. ${ }^{4} \mathrm{KD}$ is characterised by lymphoid nodules with germinal centres which may extend from the dermis to the underlying fascia and muscles. Lesions show a distinct eosinophilic infiltrate with microabscesses. Vascular proliferation is not always present; however, when seen, there are many canalised capillaries lined by flat endothelial cells. Systemic eosinophilia is almost always present, seen in approximately $98 \%$ of cases in comparison to $20 \%$ in ALHE. ${ }^{5}$

In contrast to $\mathrm{KD}$, ALHE lesions are superficial containing blood vessels of varying luminal sizes, some of which may not be canalised, lined by distinctive endothelium of an epithelioid appearance. Eosinophilic abscesses are not seen and peripheral eosinophilia is not always present. KD is thought to be an allergic response, owing to the presence of eosinophilia and elevated IgE levels, whereas ALHE is believed to be a true neoplasm of the endothelium. ${ }^{6}$

ALHE has previously been reported three times arising from the radial artery. It has not, however, been reported as arising from the axillary artery. In this case, there was no association with local trauma or infection. While ALHE is a rare condition it should be considered in the presence of peripheral vessel aneurysm formation, especially in the presence of skin lesions. 


\section{BMJ Case Reports}

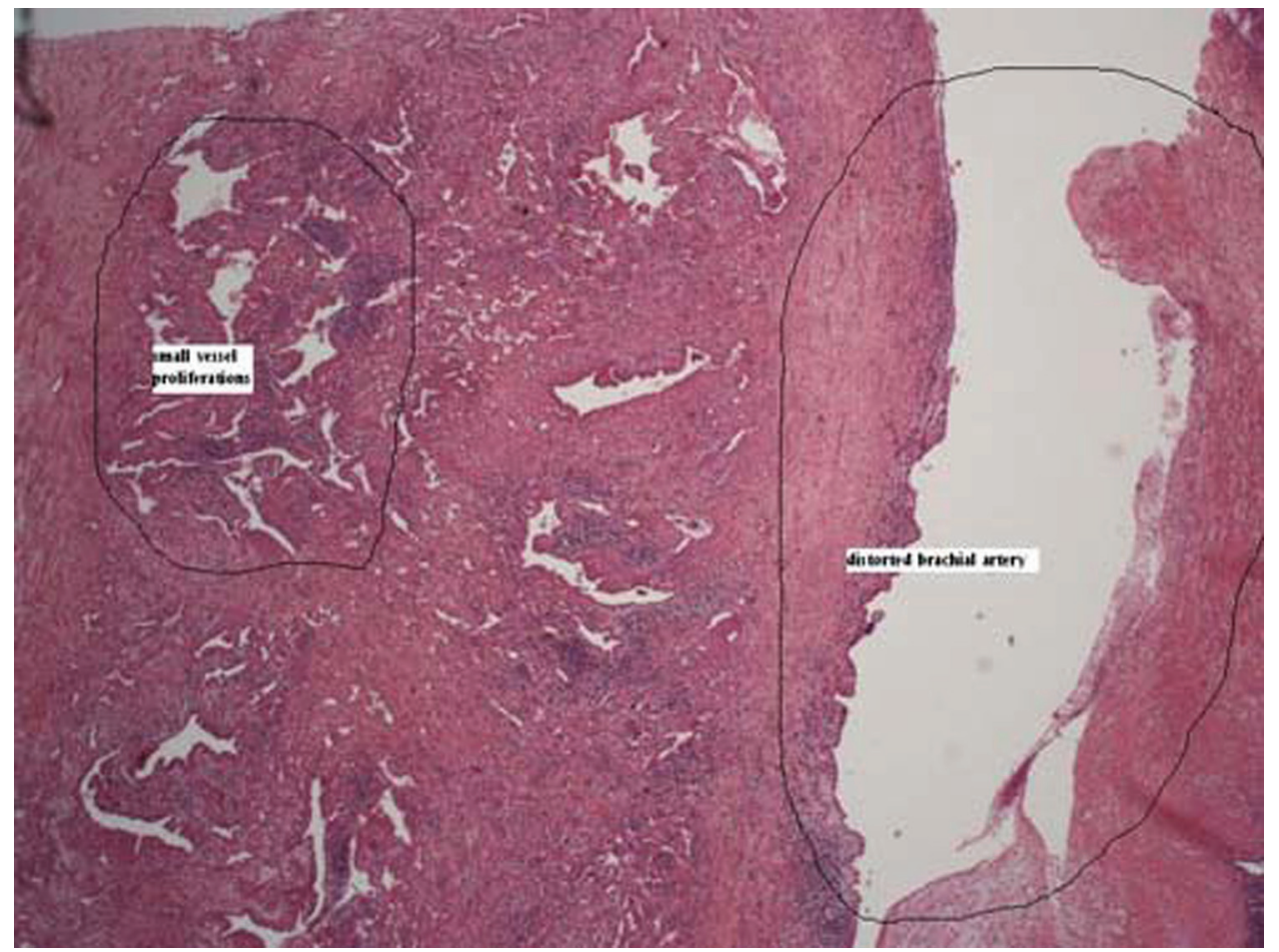

Figure 1 AHLE demonstrating distorted brachial artery and classical small vessel proliferation.

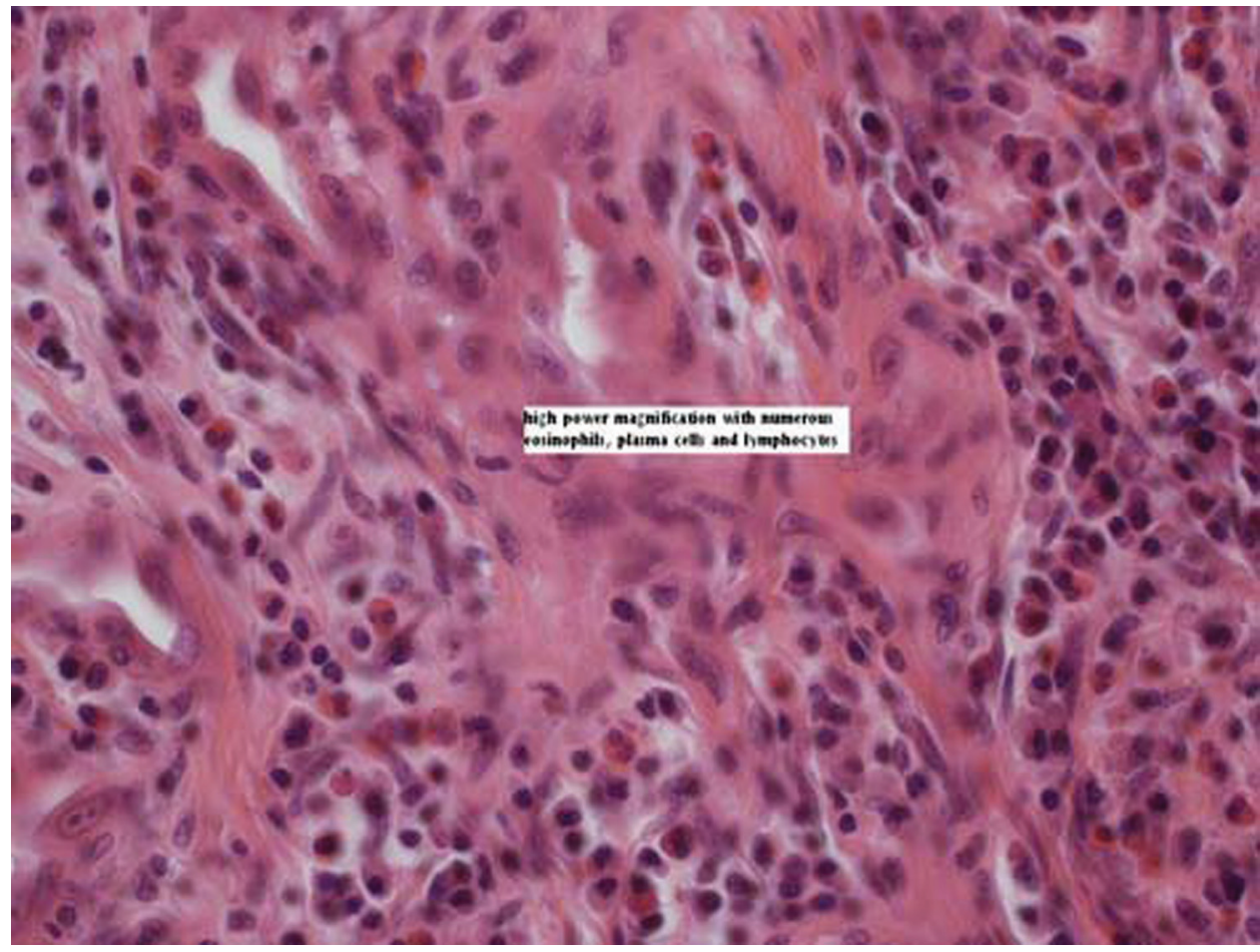

Figure 2 Higher power magnification demonstrating dense inflammatory infiltrate.

\section{TREATMENT}

Subsequent surgical repair of the axillary artery aneurysm involved complete excision of the defect followed by endto-end interposition of cephalic vein graft, taken from the patients left arm.

\section{OUTCOME AND FOLLOW-UP}

Histological examination of the excised segment revealed destruction of the arterial wall with a heavy chronic inflammatory infiltrate (including lymphocytes, plasma cells, macrophages and eosinophils) with prominent endothe- 
lial cells of epithelioid morphology. These features are characteristic of ALHE.

The graft remains patent with normal limb function at 1 year.

\section{DISCUSSION}

ALHE is characterised by solitary or multiple subcutaneous nodules with a predilection for the head and neck region. It presents in patients between 20 and 50 years of age, with a mean age at onset of 30-33 years. ${ }^{7}$ The incidence of ALHE is greater in females than in males. ${ }^{8}$ The condition is more commonly encountered in the Asian population followed by Caucasians, it is rare in the black population.

The subcutaneous lesions associated with ALHE may vary in colour, shape and size. Ranging from red to brown in colour, the lesions may be smooth or centrally eroded with crusting. The size of a single lesion may vary from 0.2 to 8 $\mathrm{cm}$, most commonly measuring $0.5-2 \mathrm{~cm}$. Approximately $80 \%$ of patients demonstrate solitary lesions, while $20 \%$ have multiple lesions clustered in one area. ${ }^{1}$ They are most commonly seen in the peri-auricular area, forehead or scalp. Rare sites of involvement include the shoulders, hands, breasts and penis. ${ }^{7}$ ALHE tends to affect the skin and subcutaneous tissues, however, it has also been described in other tissues, such as the orbit, oral mucosa, liver, spleen, heart, bone and blood vessels. ${ }^{9}$ Systemic eosinophilia of $6-34 \%$ is seen in $20 \%$ of patients. ${ }^{1}$ Regional lymphadenopathy and arteriovenous shunts have occasionally been reported but are inconsistent features.

Lesions may be asymptomatic, painful on palpation or pruritic. Some patients experience tumour pulsation and bleeding, either spontaneously or after minor frictional trauma.

The pathophysiology of this benign condition is unclear. A history of local trauma or infection is found in $9 \%$ of patients. The period between trauma and discovery of a lesion ranges between 7 months and 20 years, with a median interval of 30 months. ${ }^{1}$

The histology of ALHE shows a distinct proliferation of blood vessels with thickened walls (figure 1). These are lined with prominent epithelioid endothelial cells said to have a cobblestone appearance, some of which contain cytoplasmic vacuoles. ${ }^{10}$ Additionally, a characteristic chronic inflammatory infiltrate is seen in the perivascular and interstitial tissue, comprised of lymphocytes, plasma cells and eosinophils (figure 2). Eosinophils usually account for $5-15 \%$ of the infiltrate, though in rare cases eosinophils may account for up to $50 \% .^{7}$ Aggregation of lymphocytes is typical with a tendency to form lymphoid follicles. The lack of sinus structure indicates that these follicles arise in the subcutaneous tissue. ${ }^{11}$

Two types of ALHE lesion are described by Wells and Whimster. The early lesion demonstrates a predominance of rapidly proliferating atypical vasculature. However, late lesions illustrate maturation of these atypical blood vessels with thickened walls along with a high prevalence of lymphoid follicles seen towards the periphery of the lesion. ${ }^{12}$

ALHE rarely regresses spontaneously; however, malignant transformation does not occur. Several treatment modalities have been used, including intralesional corticosterioid injections, interferon $\alpha 2 b$, cytotoxic agents, cryotherapy, electrodessication, pulse-dye laser and carbon dioxide laser. Surgical excisions that include the arterial and venous segments at the base of the lesion are most successful, with no reported recurrence after 1 year of follow-up. ${ }^{13}$

\section{Learning points}

- Consider vasculitis as a cause of peripheral artery aneurysm.

- Complications of vasculitis induced aneurysms are the same as more common traumatic and atherosclerotic aneurysms.

- Surgical treatment of the aneurysm is required.

\section{Competing interests None.}

Patient consent Not obtained.

\section{REFERENCES}

1. Olsen TG, Helwig EB. Angiolymphoid hyperplasia with eosinophilia. A clinicopathologic study of 116 patients. J Am Acad Dermatol 1985;12 (5 Pt 1):781-96.

2. Kimm HT, Szeto C. Eosinophilic hyperblastic lymphogranuloma, comparison with Mikulicz's disease. Proc Chin Med Soc 1937;23:699-700.

3. Lee CY, Su CY, Sheen-Chen SM, et al. Kimura's disease-report of four cases. Changgeng Yi Xue Za Zhi 1994;17:153-7.

4. Googe PB, Harris NL, Mihm MC Jr. Kimura's disease and angiolymphoid hyperplasia with eosinophilia: two distinct histopathological entities. J Cutan Pathol 1987;14:263-71.

5. Lee S, James WD. Kimura Disease, 2005. www.emedicine.com/derm/ topic212.htm (accessed January 2006)

6. Rosai J, Gold J, Landy R. A unifying concept embracing several previously described entities of skin, soft tissues, large vessels, bone and heart. Human Pathol 1979;10:707-23.

7. Meyerle J, Glusac E. Angiolymphoid Hyperplasia with Eosinophilia, 2005 www.emedicine.com/derm/topic30.htm (accessed January 2006)

8. Weiss SW, Goldblum JR. Benign tumours and tumour-like lesions of blood vessels. In: Enzinger FM, Weiss SW, eds. Soft Tissue Tumours. Fourth edition. Philadelphia, PA: The CV Mosby Co 2001:856-64.

9. Moran WJ, Dobleman TJ, Bostwick DG. Epithelioid hemangioendothelioma (histiocytoid hemangioma) of the palate. Laryngoscope 1987;97:1299-302.

10. Zarrin-Khameh N, Spoden JE, Tran RM. Angiolymphoid hyperplasia with eosinophilia associated with pregnancy: a case report and review of the literature. Arch Pathol Lab Med 2005;129:1168-71.

11. Wright DH, Padley NR, Judd MA. Angiolymphoid hyperplasia with eosinophilia simulating lymphadenopathy. Histopathology 1981;5:127-40.

12. Wells GC, Whimster IW. Subcutaneous angiolymphoid hyperplasia with eosinophilia. Br J Dermato/ 1969;81:1-14.

13. Baum EW, Sams WM Jr, Monheit GD. Angiolymphoid hyperplasia with eosinophilia. The disease and a comparison of treatment modalities. J Dermatol Surg Oncol 1982;8:966-70. 


\section{BMJ Case Reports}

This pdf has been created automatically from the final edited text and images.

Copyright 2011 BMJ Publishing Group. All rights reserved. For permission to reuse any of this content visit http://group.bmj.com/group/rights-licensing/permissions.

BMJ Case Report Fellows may re-use this article for personal use and teaching without any further permission.

Please cite this article as follows (you will need to access the article online to obtain the date of publication).

Kukreja N, Koslowski M, Insall R. Angiolymphoid hyperplasia with eosinophilia presenting as an axillary artery aneurysm. BMJ Case Reports 2011: 10.1136/bcr.02.2011.3836, date of publication

Become a Fellow of BMJ Case Reports today and you can:

- Submit as many cases as you like

- Enjoy fast sympathetic peer review and rapid publication of accepted articles

- Access all the published articles

Re-use any of the published material for personal use and teaching without further permission

For information on Institutional Fellowships contact consortiasales@bmjgroup.com

Visit casereports.bmj.com for more articles like this and to become a Fellow 